\title{
THERMOGRAVIMETRIC STUDIES ON CONDENSED WOOD RESIDUES IN POLYHYDRIC ALCOHOLS LIQUEFACTION
}

\author{
Min Niu, ${ }^{a}$ Guang-jie Zhao, ${ }^{a} *$ and Mehmet Hakki Alma ${ }^{b}$
}

\begin{abstract}
To further clarify reasons for formation of condensed residues during the last stage of wood liquefaction in the medium of polyhydric alcohols and sulfuric acid catalyst, the weight loss behaviors and thermal reaction kinetics of condensed residues were studied by thermogravimetric analysis (TGA). Simultaneously, chemical methods were used to analyze the contents of lignin, cellulose, and holocellulose in the condensed residues. For all the unliquefied wood residues, the contents of cellulose decreased, and the residual ratios after TGA pyrolysis and the contents of lignin increased as a function of liquefaction time. Moreover, the highest weight loss rate went gradually to the higher temperature region after the liquefaction time and heating rate were extended. The values for apparent activation energy were lower at 150 minutes and 180 minutes and higher at 25 minutes. Liquefaction time had a smaller effect on the pyrolysis mechanism, as revealed by TGA. In conclusion, the thermal stabilities of condensed residues were higher than those of decomposed residues and wood. The condensation reaction occurred mainly during wood liquefaction, and condensed residues resulted possibly from mutual reaction among small molecules from decomposed lignin.
\end{abstract}

Keywords: Condensed residues; Wood liquefaction; Thermogravimetric analysis (TGA); Decomposed residues

Contact information: a: College of Materials Science and Technology, Beijing Forestry University, Beijing 100083, China; b: Faculty of Forestry, Kahramanmaras Sutcu Imam University, Kahramanmaras 46100, Turkey; *Corresponding author: zhaows@bjfu.edu.cn

\section{INTRODUCTION}

Solid lignocellulosic macromolecules are degraded to compounds with low molecular weight by using phenol or polyhydric alcohols as the liquefying reagents and mineral/organic acids as the catalysts at a certain temperature to prepare resoltype/polyurethane resins (Alma et al. 1998; Alma and Basturk 2006; Pan et al. 2008; Ahmadzadeh et al. 2009; Wang et al. 2009), carbon fiber (Ma and Zhao 2008), and polyurethane foams (Liu et al. 2008; Chen and Lu 2009; Kunaver et al. 2010). Considering environmental protection and biodegradability of the products, a lower amount of liquefying reagent should be added into the liquefaction system. However, according to the research of Kobayashi et al. (2004), Yamada et al. (2001), Gao and Huang (2008), Zhang et al. (2006), and Pan et al. (2007) on lignocellulosic liquefaction, less liquefying reagent caused condensation reactions to take place in the last stage of the liquefaction, and then condensation reaction caused the residual yield to increase gradually with the prolongation of liquefaction time. Undoubtedly, the availability of 
lignocellulose was reduced. To better understand these phenomena, it is necessary to study the formation reasons of the residues caused by condensation reaction (condensed residues) by many means.

Gas chromatography-mass spectrometry (GC-MS), nuclear magnetic resonance (NMR) (Lin et al. 1997a-c, 2001a,b, 2004), and Fourier transform infrared spectroscope (FTIR) (Zou et al. 2009) have been used to analyze the liquefaction reaction mechanism of the unliquefied wood residues or the liquefied wood. Thermogravimetric analysis (TGA) was also used as an effective method to reflect indirectly liquefaction mechanism by using TA60 software to calculate weight loss ratio, weight loss rate, heat absorption, and kinetic parameters of the above liquefaction products. Referring to TGA research on lignocellulose, Doh and his coworkers (2005) investigated the thermal behavior of liquefied wood polymer composites (LWPC) and indicated that the thermal stability of LWPC decreased with the increase of liquefied wood content. Wang and his coworkers (2008) studied the effects of sawdust, cellulose, hemicellulose, and lignin on weight loss ratio and weight loss rate. The results suggested that hemicellulose was the easiest to be liquefied, while lignin was the hardest component to be decomposed at high temperature. The thermal weight loss processes of not only wood and its three main components but also liquefied wood products have been studied. Ma and Zhao (2008) have investigated the TG behaviors of liquefied wood products, spinning solution, and precursors of carbon fibers prepared from liquefied wood products with phenol, and found that the weight loss rate of liquefied wood was the lowest, while the precursors of carbon fibers were the highest during the most important stage of weight loss, and the two obvious weight loss temperatures of the precursors of carbon fibers were $510{ }^{\circ} \mathrm{C}$ and $748{ }^{\circ} \mathrm{C}$. Some other research (Jong et al. 2003; Markova and Klement 2003; Fang et al. 2006; Giuntoli et al. 2009) on weight loss ratio and weight loss rate of biomass and its liquefaction products has also been done in recent years. However, weight loss processes of condensed residues in the last stage of wood liquefaction have not yet been studied totally until now.

Therefore, the goal of this paper was mainly to study TG behaviors of the condensed residues remaining in the recondensed material, to evaluate the thermal kinetic parameters, and to clarify completely the wood liquefaction mechanism, especially the condensation reaction mechanism. Meanwhile, the study of this paper will also provide a theoretical reference for the preparation of liquefied wood-based carbon fiber in a subsequent step.

\section{EXPERIMENTAL}

\section{Materials}

Birch wood (Betula dahurica Pall) was used as the raw material in order to get unliquefied wood residues, so-called decomposed and condensed residues in the presence of polyethylene glycol (PEG-400) and glycerin $(4 / 1$, w/w) with a sulfuric acid solution by concentration of $72 \%$ as a catalyst at $150{ }^{\circ} \mathrm{C}$. Wood, decomposed residues and condensed residues were used as the thermal analysis materials in this study. 


\section{Methods}

\section{Preparation of unliquefied wood residues}

Liquefaction time was viewed as a variable to evaluate the residual yield. As shown in Fig. 1, seventy minutes was the turning point for the residual yield. The residual yield decreased gradually from 10 minutes to 70 minutes, and then the yield increased slowly from 70 minutes to 180 minutes. The decomposition reaction was the most important reaction before seventy minutes, and then the condensation reaction started to be predominant in the liquefaction system. Furthermore, the residual yields of 25 minutes and 150 minutes were almost the same. The residual yields had already been analyzed in previous work (Niu et al. In press).

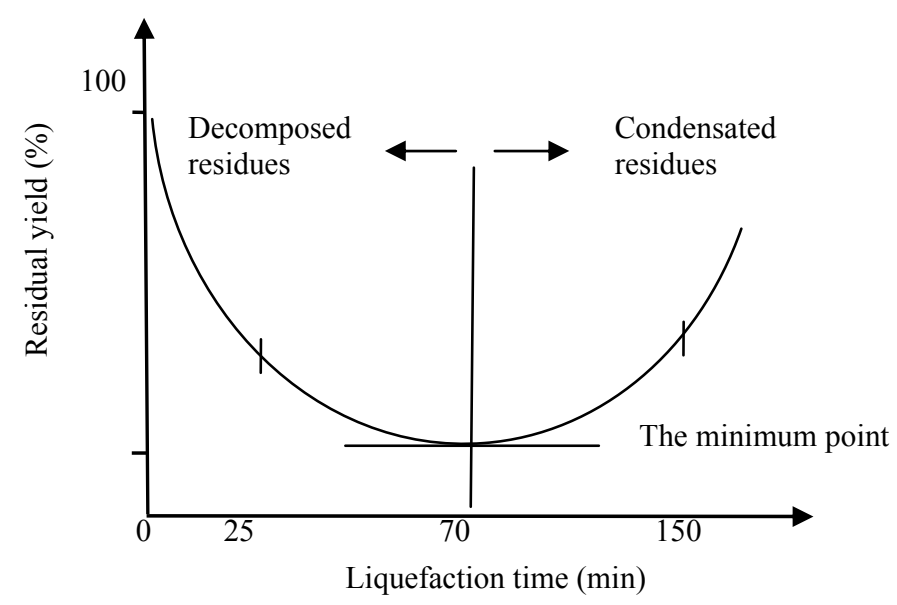

Fig. 1. A simulated profile of the relationship between liquefaction time and unliquefied wood residual yield (Polyhydric alcohols/ wood/ $72 \% \mathrm{H}_{2} \mathrm{SO}_{4}, 3 / 2 / 0.03$, w/w/w; at $150{ }^{\circ} \mathrm{C}$ )

\section{Chemical components analyses}

According to the Chinese national standard, wood and the unliquefied wood residues were first extracted for $6 \mathrm{~h}$ in a Soxhlet apparatus by benzene-alcohol $(67 / 33$, $\mathrm{v} / \mathrm{v}$ ) solution to get extractive-free materials. And then the extractive-free materials were treated by hydrogen nitrate-alcohol $(1 / 4, \mathrm{v} / \mathrm{v})$ solution for cellulose, $0.6 \mathrm{~g}$ sodium chlorite and $0.5 \mathrm{~mL}$ glacial acetic acid for holocellulose, and $72 \%$ sulfuric acid solution for Klason lignin.

\section{TG measurement}

The weight loss behaviors of wood and unliquefied wood residues were measured with a thermogravimetric analyzer (DTG-60, Shimadzu, Japan). First, 5 to $10 \mathrm{mg}$ of sample was placed in a $\mathrm{Al}_{2} \mathrm{O}_{3}$ ceramic pan. And then the samples were heated from $40^{\circ} \mathrm{C}$ to $800{ }^{\circ} \mathrm{C}$ at the heating rate of $5{ }^{\circ} \mathrm{C} / \mathrm{min}, 10^{\circ} \mathrm{C} / \mathrm{min}$, and $20^{\circ} \mathrm{C} / \mathrm{min}$, respectively. At the same time, $\mathrm{N}_{2}$ with high purity was used as a carrier gas, and the flow rate of $\mathrm{N}_{2}$ was 30 $\mathrm{mL} / \mathrm{min}$. 


\section{RESULTS AND DISCUSSION}

\section{Analyses of Chemical Components}

Table 1 presents the average contents of Klason lignin, cellulose, and holocellulose from the unliquefied wood residues subjected to different liquefaction times.

Table 1. Chemical Composition of Wood and the Unliquefied Wood Residues

\begin{tabular}{|ccccc|}
\hline Samples & $\begin{array}{c}\text { Liqu. Time } \\
(\mathrm{min})\end{array}$ & $\begin{array}{c}\text { Cellulose } \\
(\%)\end{array}$ & $\begin{array}{c}\text { Holocellulose } \\
(\%)\end{array}$ & $\begin{array}{c}\text { Klason lignin } \\
(\%)\end{array}$ \\
\hline Wood & 0 & 44.54 & 85.33 & 19.04 \\
\hline \multirow{2}{*}{$\begin{array}{c}\text { Decomposed } \\
\text { residues }\end{array}$} & 10 & 24.88 & 26.95 & 3.93 \\
\cline { 2 - 5 } & 25 & 24.92 & 27.67 & 6.09 \\
\hline \multirow{2}{*}{$\begin{array}{c}\text { Condensed } \\
\text { residues }\end{array}$} & 120 & 17.06 & 18.84 & 6.10 \\
\cline { 2 - 5 } & 150 & 12.66 & 13.96 & 7.82 \\
\hline
\end{tabular}

Notes: Temperature was $150{ }^{\circ} \mathrm{C}$; the ratio of polyhydric alcohols to wood meal was 3 to 2 ; the amount of $\mathrm{H}_{2} \mathrm{SO}_{4}$ was $1 \%$.

The contents of cellulose, holocellulose, and Klason lignin in wood were $44.54 \%$, $85.33 \%$, and $19.04 \%$, respectively. With the prolongation of liquefaction time, the contents of cellulose and holocellulose from decomposed residues decreased, which was attributed to degradation of cellulose and hemicellulose. However, the contents of cellulose, holocellulose, and Klason lignin from condensed residues increased as a function of liquefaction time, as was similar to the behavior of the residual yield in wood liquefaction. It was possible that more and more newly formed substances in the condensed residues having different molecular structures from cellulose and lignin were responsible for the observed increase of residual yield, and the chemical methods employed were insensitive to them. Pan et al. (2007) and Pu and Shiraishi (1993) also obtained the same results when less liquefying reagent was added into the liquefaction system. Compared with decomposed residues and wood itself, the contents of cellulose and holocellulose from condensed residues decreased as a whole, and the contents of Klason lignin increased obviously. It was reported that cellulose had special crystalline structure, which was a main parameter in restricting the penetrability of the liquefying reagent (Jasiukaityt et al. 2009). Therefore, of the three main components of wood, cellulose was the most different in terms of its liquefaction. On the contrary, lignin was degraded readily even in the initial stage of liquefaction (Kobayashi et al. 2004). Consequently, for the results of Table 1, it makes sense that most of the lignin in condensed residues stemmed from the condensation reaction of degraded lignin compounds. 


\section{Analyses of the Weight Loss Process}

Weight loss ratio at the three heating rates

Figure 2 shows weight loss percent as a function of temperature for wood and unliquefied wood residues as a function of the period of decomposition reaction such as 10 minutes, 25 minutes, and 60 minutes and condensation reaction such as 120 minutes, 150 minutes, and 180 minutes at the three heating rates.
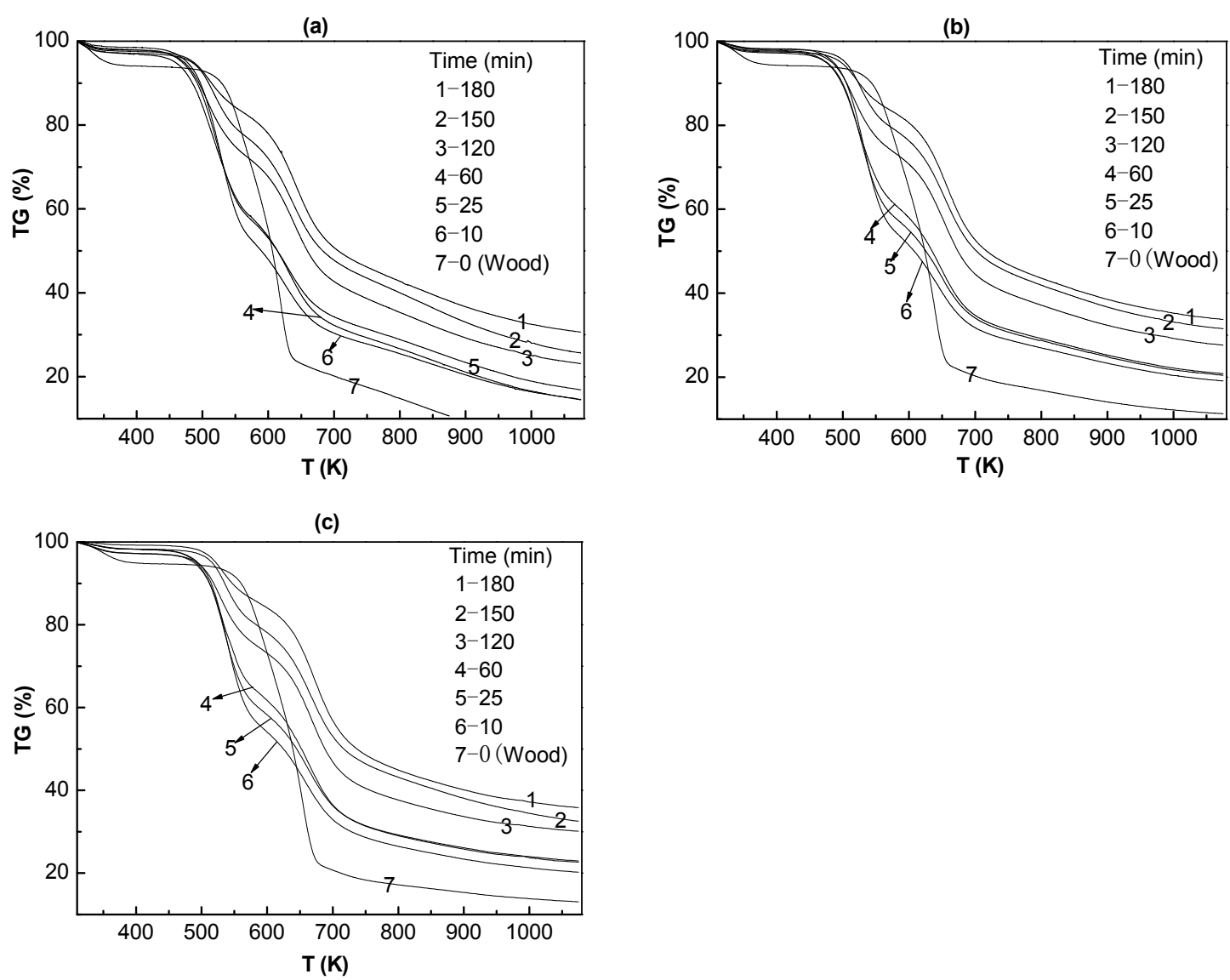

Fig. 2. TG Profiles of wood and unliquefied wood residues at $5^{\circ} \mathrm{C} / \mathrm{min}(\mathrm{a}), 10^{\circ} \mathrm{C} / \mathrm{min}$ (b), and 20 ${ }^{\circ} \mathrm{C} / \mathrm{min}(\mathrm{c})$ under nitrogen

As can be seen in Fig. 2, the weight loss process of all the samples could be partitioned into three stages (Stages a-c). These can be described as a mild weight loss (Stage a), a sharp weight loss (Stage b), and a slow weight loss (Stage c). As a matter of fact, the sharp weight loss stage for the residues could be specifically redivided into two shorter processes, which was different from the TG profile of wood. Finally, the two shorter processes were merged into one longer stage in order to conveniently compare the weight loss ratio between wood itself and the unliquefied wood residues. The temperature ranges, weight loss percents, and the residual ratios of all the samples were analyzed by the TA60 software, and the results are listed in Table 2. 
Table 2. TG Weight Loss Percents and Residual Ratios for all the Samples (wood, decomposed and condensed residues) at the Three Heating Rates

\begin{tabular}{|c|c|c|c|c|c|}
\hline \multirow[t]{2}{*}{$\begin{array}{l}\text { Liqu. Time } \\
\text { (min) }\end{array}$} & \multirow{2}{*}{$\begin{array}{l}\text { Heating rate } \\
\left({ }^{\circ} \mathrm{C} / \mathrm{min}\right)\end{array}$} & \multicolumn{3}{|c|}{$\begin{array}{c}\text { Temp. range }(\mathrm{K}) \\
\text { Weight loss percent }(\%)\end{array}$} & \multirow{2}{*}{$\begin{array}{c}\text { Residual ratio } \\
(\%)\end{array}$} \\
\hline & & Stage a & Stage $b$ & Stage c & \\
\hline \multirow{3}{*}{0} & 5 & $\begin{array}{c}313-502 \\
7.10\end{array}$ & $\begin{array}{c}502-643 \\
68.83\end{array}$ & $\begin{array}{l}643-873 \\
13.01\end{array}$ & 11.16 \\
\hline & 10 & $\begin{array}{c}313-502 \\
6.44 \\
\end{array}$ & $\begin{array}{c}502-666 \\
70.76 \\
\end{array}$ & $\begin{array}{c}666-1073 \\
11.12 \\
\end{array}$ & 15.17 \\
\hline & 20 & $\begin{array}{c}313-502 \\
5.61\end{array}$ & $\begin{array}{l}502-688 \\
72.93\end{array}$ & $\begin{array}{c}688-1073 \\
7.97\end{array}$ & 16.23 \\
\hline \multirow{3}{*}{10} & 5 & $\begin{array}{c}313-444 \\
2.16 \\
\end{array}$ & $\begin{array}{c}444-724 \\
68.68\end{array}$ & $\begin{array}{c}724-1073 \\
14.39 \\
\end{array}$ & 14.77 \\
\hline & 10 & $\begin{array}{c}313-444 \\
2.02 \\
\end{array}$ & $\begin{array}{c}444-761 \\
69.36 \\
\end{array}$ & $\begin{array}{l}761-1073 \\
9.31 \\
\end{array}$ & 19.31 \\
\hline & 20 & $\begin{array}{c}313-444 \\
2.08\end{array}$ & $\begin{array}{l}444-837 \\
72.56\end{array}$ & $\begin{array}{c}837-1073 \\
4.99\end{array}$ & 20.37 \\
\hline \multirow{3}{*}{25} & 5 & $\begin{array}{c}313-438 \\
2.47 \\
\end{array}$ & $\begin{array}{l}438-728 \\
64.62\end{array}$ & $\begin{array}{l}728-1073 \\
14.53 \\
\end{array}$ & 17.38 \\
\hline & 10 & $\begin{array}{c}313-438 \\
2.66\end{array}$ & $\begin{array}{c}438-770 \\
67.21\end{array}$ & $\begin{array}{l}770-1073 \\
9.33\end{array}$ & 20.80 \\
\hline & 20 & $\begin{array}{c}313-438 \\
1.88\end{array}$ & $\begin{array}{c}438-846 \\
70.28\end{array}$ & $\begin{array}{l}846-1073 \\
4.70\end{array}$ & 23.14 \\
\hline \multirow{3}{*}{60} & 5 & $\begin{array}{c}313-429 \\
3.30\end{array}$ & $\begin{array}{l}429-730 \\
65.75\end{array}$ & $\begin{array}{l}730-1073 \\
15.69\end{array}$ & 15.26 \\
\hline & 10 & $\begin{array}{c}313-446 \\
3.22\end{array}$ & $\begin{array}{l}446-758 \\
65.48\end{array}$ & $\begin{array}{l}758-1073 \\
10.06\end{array}$ & 21.24 \\
\hline & 20 & $\begin{array}{c}313-451 \\
3.04\end{array}$ & $\begin{array}{l}451-839 \\
67.88\end{array}$ & $\begin{array}{l}839-1073 \\
4.94\end{array}$ & 23.14 \\
\hline \multirow{3}{*}{120} & 5 & $\begin{array}{c}313-453 \\
3.23 \\
\end{array}$ & $\begin{array}{c}453-721 \\
55.53 \\
\end{array}$ & $\begin{array}{l}721-1073 \\
17.48 \\
\end{array}$ & 23.76 \\
\hline & 10 & $\begin{array}{c}313-453 \\
2.80\end{array}$ & $\begin{array}{l}453-805 \\
60.02\end{array}$ & $\begin{array}{l}805-1073 \\
9.10\end{array}$ & 27.98 \\
\hline & 20 & $\begin{array}{c}313-453 \\
3.06\end{array}$ & $\begin{array}{l}453-916 \\
63.43\end{array}$ & $\begin{array}{l}916-1073 \\
2.98\end{array}$ & 30.53 \\
\hline \multirow{3}{*}{150} & 5 & $\begin{array}{c}313-465 \\
3.65 \\
\end{array}$ & $\begin{array}{c}465-733 \\
51.20\end{array}$ & $\begin{array}{l}733-1073 \\
18.93 \\
\end{array}$ & 26.22 \\
\hline & 10 & $\begin{array}{l}313-465 \\
2.36\end{array}$ & $\begin{array}{l}465-810 \\
55.86\end{array}$ & $\begin{array}{l}810-1073 \\
8.79\end{array}$ & 32.09 \\
\hline & 20 & $\begin{array}{c}313-465 \\
1.97 \\
\end{array}$ & $\begin{array}{c}465-836 \\
56.56\end{array}$ & $\begin{array}{l}836-1073 \\
8.60\end{array}$ & 32.87 \\
\hline \multirow{3}{*}{180} & 5 & $\begin{array}{c}313-461 \\
3.15 \\
\end{array}$ & $\begin{array}{c}461-727 \\
48.71\end{array}$ & $\begin{array}{l}727-1073 \\
7.24 \\
\end{array}$ & 30.90 \\
\hline & 10 & $\begin{array}{c}313-461 \\
2.92 \\
\end{array}$ & $\begin{array}{l}461-806 \\
53.55\end{array}$ & $\begin{array}{l}806-1073 \\
9.41\end{array}$ & 34.12 \\
\hline & 20 & $\begin{array}{c}313-461 \\
1.26\end{array}$ & $\begin{array}{l}461-877 \\
57.16\end{array}$ & $\begin{array}{c}877-1073 \\
5.14\end{array}$ & 36.44 \\
\hline
\end{tabular}

Two variables are presented in Fig. 2 and Table 2, the heating rate and the liquefaction time. In the Stage $b$, a higher heating rate resulted in higher weight loss percent and provided worse thermal stability. In the Stages a and c of TGA pyrolysis, the 
higher the heating rate was, the lower was the weight loss ratio, which agrees with the findings of Doh et al. (2005), who reported that a higher heating rate provided higher thermal stability, resulting from the decelerated decomposition rate. When the heating rate was equal in Table 2, for condensed residues, the weight loss percents from the three weight loss stages decreased generally, and the residual ratios after TGA pyrolysis increased with the extension of liquefaction time. The reason was possibly that the residue that was exposed for a longer liquefaction time gave more substances whose thermal stability was better than in the case of a shorter liquefaction time. Simultaneously, the highest lignin content of the liquefaction residue at 180 minutes resulted possibly in the highest residual ratio in TGA pyrolysis (Wu et al. 2009; Huang 2007).

Compared with decomposed residues and wood itself, the weight loss percents of condensed residues in the Stage $b$ were lower, and the residual ratios were higher. All of these suggested that the thermal decomposition rates of condensed residues were the lowest and their thermal stabilities were the best. The reason was also consistent with a higher content of lignin, as shown in Table 1. Lin and his coworkers (Lin et al. 1997a-c, 2001a, b) have studied the liquefaction mechanism of model compounds of lignin. They found that the liquefaction products were mainly compounds with polyphenolic structure, such as the structurally stable guaiacyl unit. On the one hand, these compounds reacted with each other and formed thermally stable substances with higher molecular weight. On the other hand, they might react with the aldehydes from oxidated liquefying reagents of this study, forming a thermoplastic phenolic resin. It was well known that phenolic resin can have a higher thermal stability and carbonization yield at high temperature (Zhou 2000).

\section{Weight loss rate at the three heating rates}

Figure 3 shows that DTG profiles from wood, decomposed, and condensed residues from different liquefaction times at the different heating rates. From the DTG profiles there were obvious differences among wood, decomposed residues, and condensed residues. Only one sharp peak occurred on the DTG curve of wood after $600 \mathrm{~K}$; however, two peaks appeared on the curves of the unliquefied wood residues. One was lower than $600 \mathrm{~K}$, and another was higher than $600 \mathrm{~K}$. In the entire liquefaction process, the first one on the DTG curve became lower little by little, and the second one became higher increasingly as a function of liquefaction time. There seemed to be a transition period near to 120 minutes for the DTG profiles of the two liquefaction residues, and the two peak heights were almost at the same level. The DTG profile is a result of differential calculation for TG data, so a higher peak stands for a higher weight loss rate. The differences on the DTG profiles indicated that the temperature at which weight loss rate was up to the maximum became gradually higher with prolongation of the liquefaction time.

The DTG peak from wood was the highest, and the corresponding peak from condensed residues was the lowest among all the samples, which was in the agreement with the results of weight loss percent analyses, suggesting that condensed residues were harder to be decomposed in TGA pyrolysis because of their special molecular structure. 

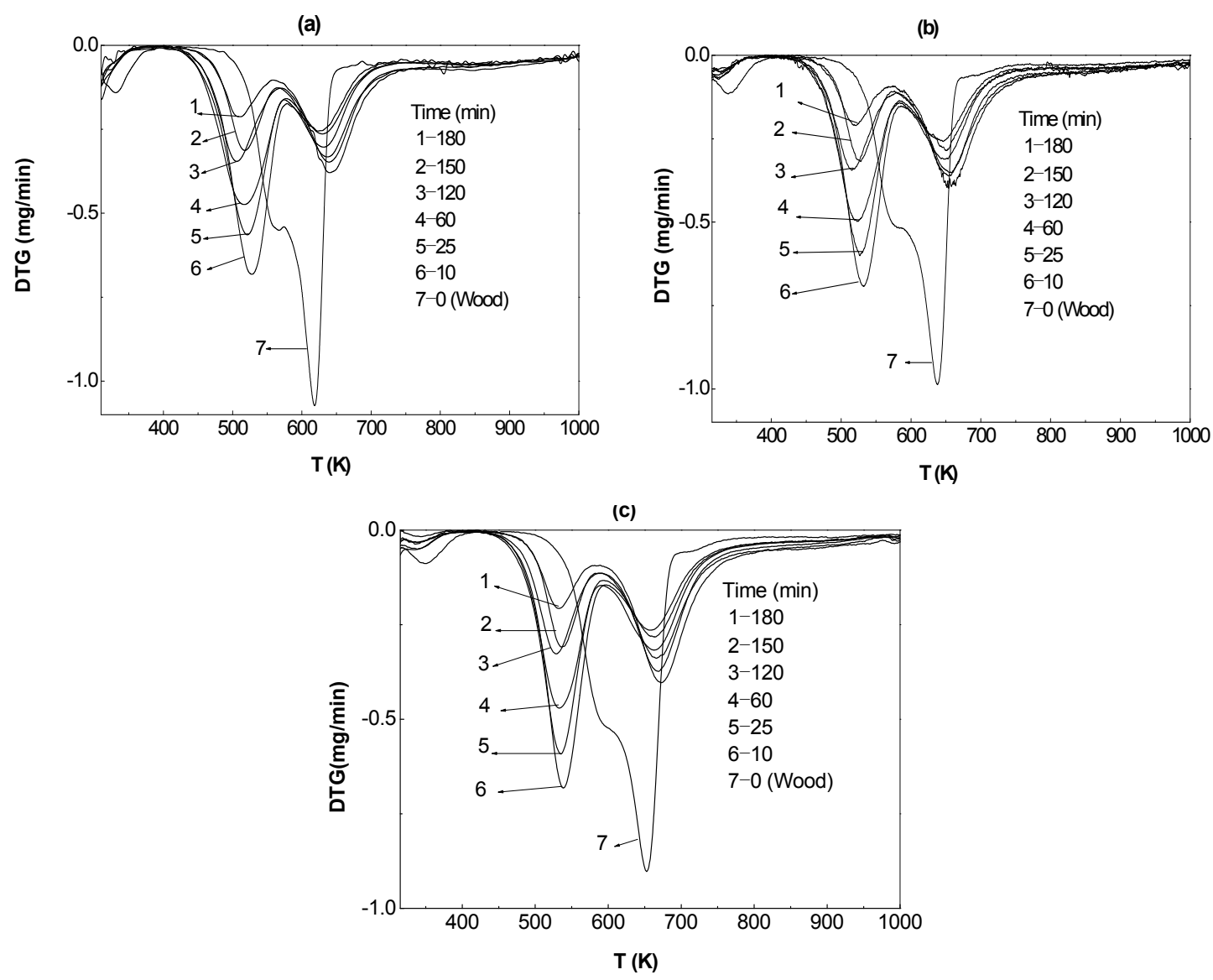

Fig. 3. DTG profiles for all the samples (wood, decomposed and condensed residues) at $5{ }^{\circ} \mathrm{C}$ $/ \mathrm{min}(\mathrm{a}), 10^{\circ} \mathrm{C} / \mathrm{min}(\mathrm{b})$, and $20^{\circ} \mathrm{C} / \mathrm{min}$ (c) under nitrogen

\section{Heat absorption values of the samples in TGA pyrolysis}

For Stage b, which was the most predominant in the process of weight loss, heat absorption values of all the samples showed a maximum. In addition, the highest heating rate brought the sharpest peak and finally made the analysis of heat absorption maintain greater accuracy. So the heating rate of $20{ }^{\circ} \mathrm{C} / \mathrm{min}$ was chosen as a parameter to get a series of differential thermal analysis (DTA) profiles. Figure 4 displays DTA profiles of all the samples at $20^{\circ} \mathrm{C} / \mathrm{min}$ in the Stage $\mathrm{b}$ of TGA pyrolysis under nitrogen.

DTA profiles of all the liquefied residues were totally different from that of wood itself, and their heat absorption peaks occurred within a lower temperature zone. Moreover, the shape of the peaks from condensed and decomposed residues had smaller differences. Heat absorption values and peak temperature of all the samples in TGA pyrolysis at $20^{\circ} \mathrm{C} / \mathrm{min}$ are listed in Table 3 . 


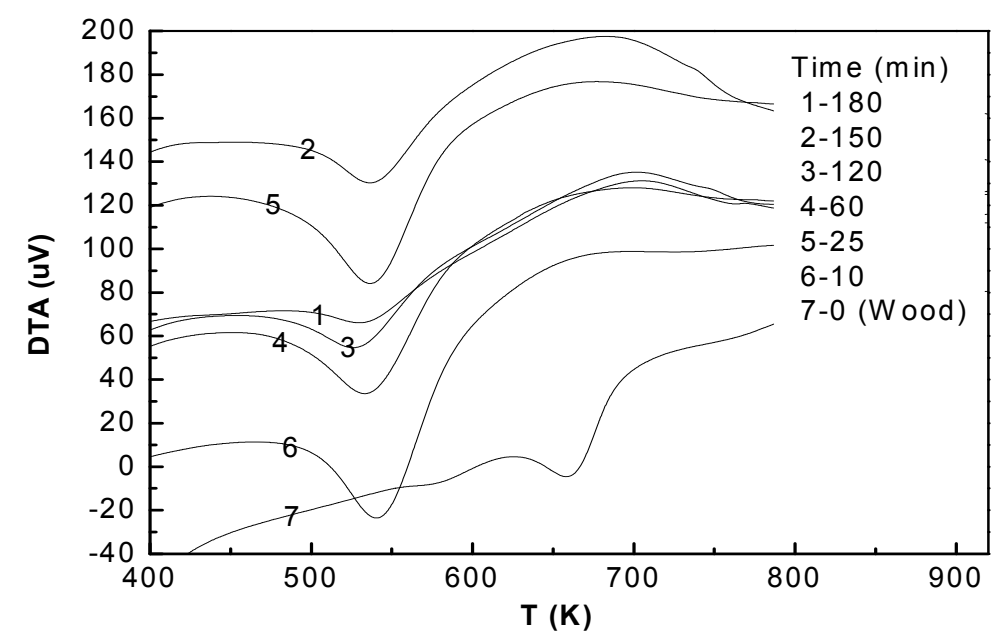

Fig. 4. DTA profiles of wood, decomposed and condensed residues at $20^{\circ} \mathrm{C} / \mathrm{min}$

Table 3. Heat Absorption Values of Wood and the Unliquefied Wood Residues in Stage b of DTG Pyrolysis

\begin{tabular}{|ccc|}
\hline $\begin{array}{c}\text { Liqu. Time } \\
(\mathrm{min})\end{array}$ & $\begin{array}{c}\text { Peak Temp. } \\
\left({ }^{\circ} \mathrm{C}\right)\end{array}$ & $\begin{array}{c}\text { Heat absorption } \\
(\mathrm{J} / \mathrm{g})\end{array}$ \\
\hline 0 (wood) & 658.20 & 431.21 \\
\hline 10 & 540.56 & 1370.00 \\
\hline 25 & 536.48 & 1850.00 \\
\hline 60 & 533.08 & 1110.00 \\
\hline 120 & 525.87 & 864.00 \\
\hline 150 & 536.45 & 915.39 \\
\hline 180 & 529.87 & 436.66 \\
\hline
\end{tabular}

The heat absorption values of condensed residues in TGA pyrolysis were nearly half of those of decomposed residues, although peak temperatures of the two unliquefied wood residues were similar. It was possible that less active substances in the condensed residues were not sensitive to higher temperature and they might not participate in the TGA pyrolysis reaction. The heat absorption value of condensed residue at 180 minutes was up to the minimum, and it approached the heat absorption value of wood itself. This was because the condensed residue at 180 minutes contained more thermally stable substances. Meanwhile, in the case of wood, a higher hemicellulose content was a reason for lower heat absorption. Besides, the heat absorption of condensed residue at 150 minutes was lower than that of the residue at 25 minutes even if they had equal liquefaction residual yield and peak temperature of DTA. From the analyses of chemical components of the unliquefied wood residues, the liquefaction residue at 25 minutes contained the highest contents of cellulose and holocellulose compared with other unliquefied wood residues, which might be the cause of the highest heat absorption value. 


\section{Non-Isothermal Thermogravimetric Kinetics}

In the study on TG, $\alpha$ can be regarded as the conversion of the reactant at time $t$, which follows from Eq. 1,

$$
\alpha=\frac{W_{0}-W_{t}}{W_{0}-W_{\infty}}
$$

where $W_{0}$ is the initial mass before pyrolysis, $W_{t}$ is the mass of the sample when the reaction time is $t$, and $W_{\infty}$ stands for the residual mass of the sample after the reaction is completed.

The relationship between the conversion $(\alpha)$ and reaction rate $(k)$ can be expressed as in Eq. 2,

$$
\frac{d \alpha}{d t}=k(1-\alpha)^{n}
$$

where $(\mathrm{d} \alpha / \mathrm{d} t)$ is the conversion rate, $n$ is the reaction order, which can be a fraction and negative, and $k$ is the rate constant given by the Arrhenius Eq. 3,

$$
K=A \exp \left(-\frac{E}{R T}\right)
$$

where $A$ is an apparent pre-exponential factor, $R$ is the gas constant, $T$ is the absolute temperature, and $E$ is the apparent activation energy. Eq. 4 is obtained by combining Eqs. 2 and 3 ,

$$
\frac{d \alpha}{d t}=A \exp \left(-\frac{E}{R T}\right)(1-\alpha)^{n}
$$

According to the method of Kissinger (1957), Eq. 4 can be further transformed to the Eq. 5,

$$
\ln \left(\frac{\beta_{i}}{T_{p i}{ }^{2}}\right)=\ln \frac{A_{\alpha} R}{E_{\alpha}}-\frac{E_{\alpha}}{R} \frac{1}{T_{p i}}[\mathrm{i}=1,2, \cdots, 6]
$$

where $\beta$ is the heating rate and $\beta=\mathrm{d} T / \mathrm{d} t$. By using Eq. 5, a linear function can be built by $\ln \left(\beta / T_{p}{ }^{2}\right)$ and $1 / T_{p}$. $E_{\alpha}$ values of all the samples can be determined from the slopes of the straight line. $A_{\alpha}$ values can also be calculated by the intercepts of the straight line. Theoretically, there are at least two points required to build a straight line; however, considering the experimental errors, three peak temperatures $\left(T_{p}\right)$ from DTA profiles in accordance with three heating rate $\beta=5,10$, and $20^{\circ} \mathrm{C} / \mathrm{min}$ can be found to draw a straight line. The linear relationships between $\ln \left(\beta / T_{p}{ }^{2}\right)$ and $1 / T_{p}$ are displayed in Figs. 5 and 7.

Furthermore, a simplified equation from Crane (1972) was used to work out the reaction order $n$, 


$$
\ln \beta=-\frac{E_{a}}{n R} \times \frac{1}{T_{P}}+C
$$

Therefore, the reaction order $n$ can be calculated according to the slopes of the straight line represented by Eq. 6. The linear relationships between $\ln \beta$ and $1 / T_{P}$ are presented in Figs. 6 and 7.

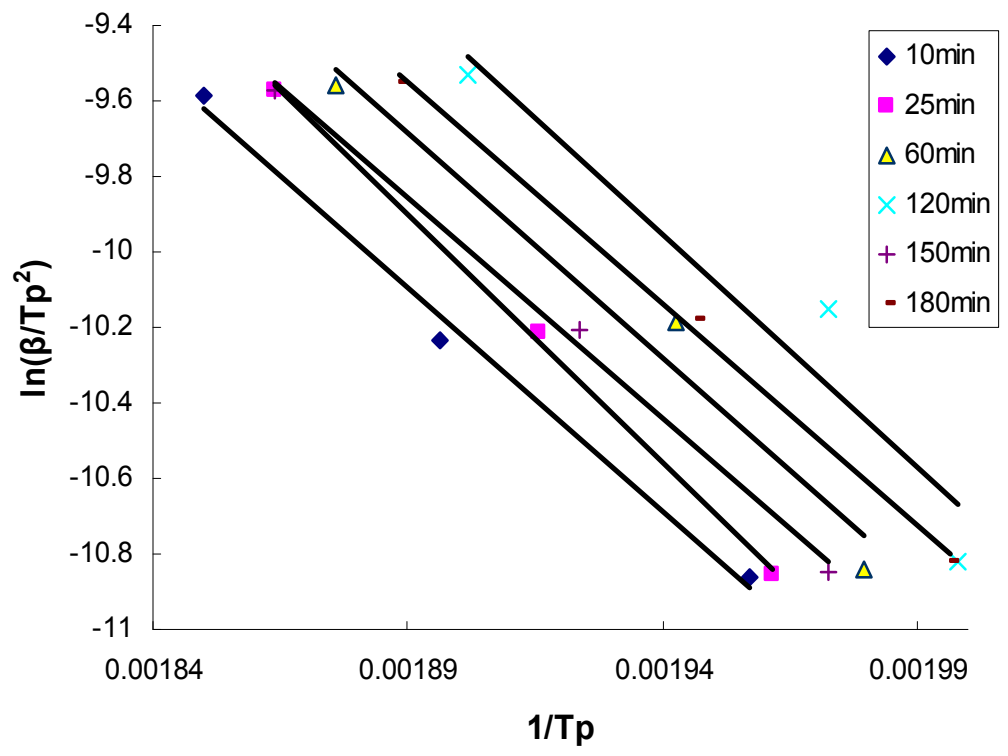

Fig. 5. Linear relationship between $\ln \left(\beta / T_{p}{ }^{2}\right)$ and $1 / T_{p}$ during TGA pyrolysis of the unliquefied wood residues

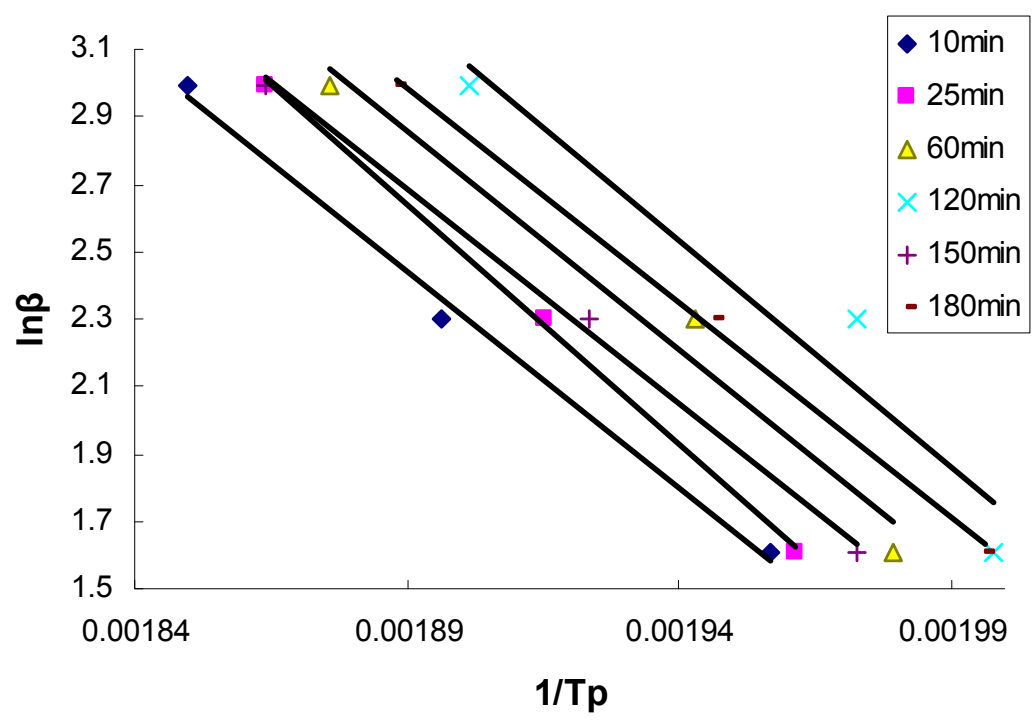

Fig. 6. Linear relationship between $\ln \beta$ and $1 / T_{p}$ during TGA pyrolysis of the unliquefied wood residues 


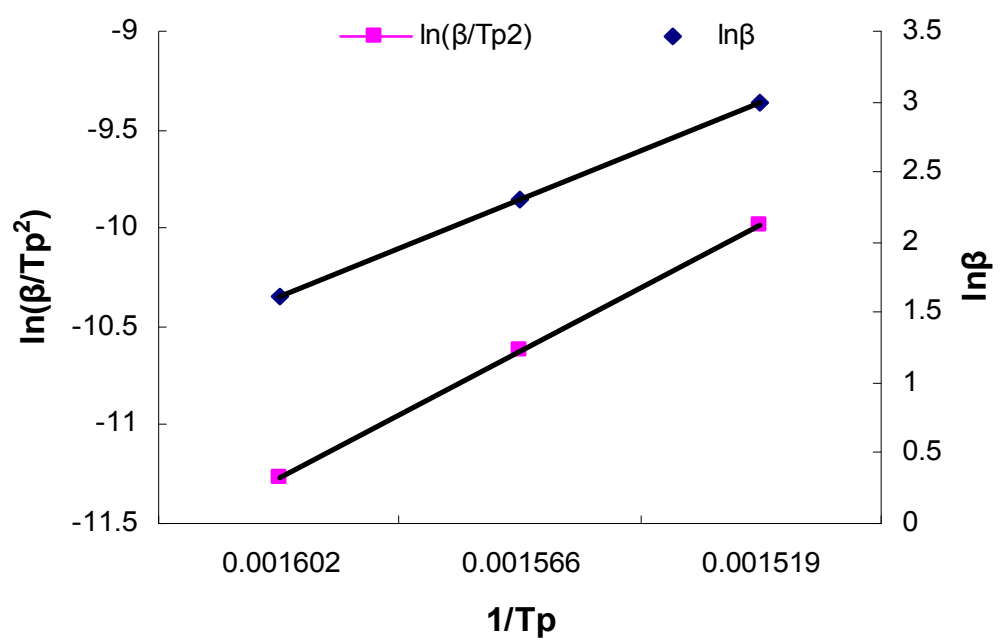

Fig. 7. Linear relationships between $\ln \beta, \ln \left(\beta / T_{p}^{2}\right)$, and $1 / T_{p}$ during TGA pyrolysis of wood

According to the linear relationships in Figs. 5 to 7, the calculated results of the three kinetic parameters and the correlation coefficients $\left(R^{2}\right)$ of the $E_{\alpha}$ and $n$ values for all the samples are listed in Table 4.

Table 4. Kinetic Parameters of All the Samples at the Three Heating Rates

\begin{tabular}{|c|c|c|c|c|c|}
\hline $\begin{array}{l}\text { Liqu. } \\
\text { Time } \\
\text { (min) }\end{array}$ & $\begin{array}{l}\text { Heating } \\
\text { rate } \\
\left({ }^{\circ} \mathrm{C} / \mathrm{min}\right)\end{array}$ & $\begin{array}{c}\text { Peak } \\
\text { Temp. (K) }\end{array}$ & $\begin{array}{c}E_{\alpha}\left(R^{2}\right) \\
(k J / m o l)\end{array}$ & $\begin{array}{c}A_{\alpha} \\
\left(\times 10^{8} s^{-1}\right)\end{array}$ & $n\left(R^{2}\right)$ \\
\hline \multirow{3}{*}{0} & 5 & 624.35 & \multirow{3}{*}{$128.55(0.9940)$} & \multirow{3}{*}{117} & \multirow{3}{*}{$0.9234(0.9950)$} \\
\hline & 10 & 638.75 & & & \\
\hline & 20 & 658.20 & & & \\
\hline \multirow{3}{*}{10} & 5 & 511.01 & \multirow{3}{*}{$98.41(0.9936)$} & \multirow{3}{*}{25.40} & \multirow{3}{*}{$0.9185(0.9945)$} \\
\hline & 10 & 527.28 & & & \\
\hline & 20 & 540.56 & & & \\
\hline \multirow{3}{*}{25} & 5 & 509.80 & \multirow{3}{*}{$109.33(0.9987)$} & \multirow{3}{*}{409} & \multirow{3}{*}{$0.9263(0.9989)$} \\
\hline & 10 & 522.05 & & & \\
\hline & 20 & 536.48 & & & \\
\hline \multirow{3}{*}{60} & 5 & 505.20 & \multirow{3}{*}{$99.58(0.9668)$} & \multirow{3}{*}{50.50} & \multirow{3}{*}{$0.9202(0.9720)$} \\
\hline & 10 & 514.70 & & & \\
\hline & 20 & 533.08 & & & \\
\hline \multirow{3}{*}{120} & 5 & 500.51 & \multirow{3}{*}{$102.74(0.9190)$} & \multirow{3}{*}{152} & \multirow{3}{*}{$0.9232(0.9303)$} \\
\hline & 10 & 506.94 & & & \\
\hline & 20 & 525.87 & & & \\
\hline \multirow{3}{*}{150} & 5 & 506.92 & \multirow{3}{*}{$97.12(0.9960)$} & \multirow{3}{*}{23.70} & \multirow{3}{*}{$0.9180(0.9967)$} \\
\hline & 10 & 519.80 & & & \\
\hline & 20 & 536.45 & & & \\
\hline \multirow{3}{*}{180} & 5 & 500.86 & \multirow{3}{*}{$97.69(0.9975)$} & \multirow{3}{*}{36.90} & \multirow{3}{*}{$0.9193(0.9979)$} \\
\hline & 10 & 513.68 & & & \\
\hline & 20 & 529.57 & & & \\
\hline
\end{tabular}


In general, the apparent activation energy $\left(E_{\alpha}\right)$ increased with the increase of the apparent pre-exponential factor $\left(A_{\alpha}\right)$ in agreement with Eq. 5. The $E_{\alpha}$ values ranged from 97.12 to $128.55 \mathrm{~kJ} / \mathrm{mol}$. The $E_{\alpha}$ values of the unliquefied wood residues decreased after wood was liquefied, and the $E_{\alpha}$ values at 150 minutes and 180 minutes were the lowest for all the unliquefied wood residues. Yan and his coworkers (1997) studied the apparent activation energy of several kinds of wood, $\alpha$-cellulose, and Klason lignin from the same wood samples. They obtained $E_{\alpha}$ values in the range 85.54 to $101.85 \mathrm{~kJ} / \mathrm{mol}$, 165.62 to $195.78 \mathrm{~kJ} / \mathrm{mol}$, and 24.54 to $36.07 \mathrm{~kJ} / \mathrm{mol}$, respectively. Obviously, the $E_{\alpha}$ value from cellulose was the highest and that corresponding to lignin was the lowest in the process of TGA pyrolysis. In other words, higher cellulose content or lower content of lignin in lignocellulose could bring higher $E_{\alpha}$ value in the lignocellulosic pyrolysis. The same explanations also can account for the observation of higher $E_{\alpha}$ value at 25 minutes and lower E values at 150 minutes and 180 minutes.

As for the reaction order $n$, it was distributed in the range from 0.9180 to 0.9263 for all the samples, and there was little difference among wood, decomposed, and condensed residues. It is suggested that the liquefaction time did not have a significant effect on the pyrolysis reaction mechanism. And the ranges of the correlation coefficients corresponding with the $E_{\alpha}$ and the $n$ values were respectively 0.9190 to 1 and 0.9303 to 0.9989 , which suggested that the results of linear fitting were better for the $E_{\alpha}$ and $n$ parameters.

\section{CONCLUSIONS}

1. The contents of cellulose and holocellulose from condensed residues were lower and the contents of lignin were higher than those of decomposed residues. The content of lignin at 180 minutes was up to $36.05 \%$, which was almost twice as much as wood.

2. The weight loss process of all the samples could be divided into three stages in TGA pyrolysis. The weight loss percents of condensed residues in the main pyrolysis stage decreased, and the residual ratios increased with the prolongation of liquefaction time. Compared with decomposed residues and wood itself, the residual ratios of condensed residues were higher and heat absorption values were lower. And the highest weight loss rate went increasingly to the higher temperature region when liquefaction time was prolonged.

3. The $E_{\alpha}$ values of unliquefied wood residues were lower than that of wood itself. The value was up to the maximum at 25 minutes, which was attributable to higher contents of cellulose and holocellulose, whereas at 150 minutes and 180 minutes the values were lower due to higher contents of lignin. Furthermore, the liquefaction time had a small effect on the TGA pyrolysis mechanism.

4. In summary, the condensed residues had better thermal stability and they were mainly derived from the mutual condensation reaction among small molecules from the cleaved lignin. 


\section{ACKNOWLEDGMENTS}

The authors are grateful for the support of Forestry Public Special Scientific Research in China, Grant. No. 2010-04057.

\section{REFERENCES CITED}

Ahmadzadeh, A., Zakaria, S., and Rashid, R. (2009). "Liquefaction of oil palm empty fruit bunch (EFB) into phenol and characterization of phenolated EFB resin," Industrial Crops and Products 30(1), 54-58.

Alma, M. H., and Basturk, M. A. (2006). "Liquefaction of grapevine cane (Vitis Vinisera L.) waste and its application to phenol-formaldehyde type adhesive," Industrial Crops and Products 24(2), 171-176.

Alma, M. H., Yoshioka, M., Yao, Y., and Shiraishi, N. (1998). "Preparation of sufuric acid-catalyzed phenolated wood resin," Wood Science and Technology 32(4), 297308.

Chen, F. G., and Lu, Z. M. (2009). "Liquefaction of wheat straw and preparation of rigid polyurethane foam from the liquefaction products," J. Applied Polymer Science 111(1), 508-516.

Crane, L. W. (1972). "Analysis of curing kinetics in polymer composites," Polymer Science 12, 120-131.

Doh, G. H., Lee, S. Y., Kang, I. A., and Kong, Y. T. (2005). "Thermal behavior of liquefied wood polymer composites (lwpc)," Composite Structures 68(1), 103-108.

Fang, M. X., Shen, D. K., Li, Y. X., Yu, C. J., Luo, Z. Y., and Cen, K. F. (2006). "Kinetic study on pyrolysis and combustion of wood under different oxygen concentrations by using TG-FTIR analysis," J. Analytical and Applied Pyrolysis 77(1), 22-27.

Gao, G. H., and Huang, J. T. (2008). "Separation of liquefied product of salix psammophila by column chromatography and structure analysis of its components," Forestry Studies in China 10(4), 274-279.

Giuntoli, J., Arvelakis, S., Spliethoff, H., Jong, W. D., and Verkooijen, A. H. M. (2009). "Quantitative and kinetic thermogravimetric Fourier transform infrared (TG-FTIR) study of pyrolysis of agricultural residues: Influence of different pretreatments," Energy \& Fuels 23, 5695-5706.

Huang, N., Gao, D. W., Li J. W., and Chen, B. H. (2007). "Comparison of the pyrolysis and kinetics of three components of biomass," J. Beijing University of Chemical Technology 34(5), 462-466.

Jasiukaityt, E., Kunaver, M., and Strli, M. (2009). "Cellulose liquefaction in acidified ethylene glycol," Cellulose 16(3), 393-405.

Jong, W. D., Pirone, A., and Wojtowicz, M. A. (2003). "Pyrolysis of miscanthus giganteus and wood pellets: TG-FTIR analysis and reaction kinetics," Fuel 82(9), 1139-1147.

Kissinger, H. E. (1957). "Reaction kinetics in differential thermal analysis," Analytical Chemistry 29(11), 1702-1706. 
Kobayashi, M., Asano, T., Kajiyama, M., and Tomita, B. (2004). "Analysis on residue formation during wood liquefaction with polyhydric alcohol," J. Wood Science 50(5), 407-414.

Kunaver, M., Jasiukaityte, E., Cuk, N., and Guthrie, J. T. (2010) "Liquefaction of wood, synthesis and characterization of liquefied wood polyester derivatives," J. Applied Polymer Science 115(3), 1265-1271.

Lin, L. Z., Yao, Y. G., and Shiraishi, N. (2001a). "Liquefaction mechanism of $\beta$-o-4 lignin model compound in the presence of phenol under acid catalysis. Part 1. Identification of the reaction products," Holzforschung 55(6), 617-624.

Lin, L. Z., Yao, Y. G., and Shiraishi, N. (2001b). "Liquefaction mechanism of $\beta$-o-4 lignin model compound in the presence of phenol under acid catalysis. Part 2. Reaction behavior and pathways," Holzforschung 55(6), 625-630.

Lin, L. Z., Yao, Y. G., Yoshioka, M., and Shiraishi, N. (1997a). "Liquefaction mechanism of lignin in the presence of phenol at elevated temperature without catalysts: Studies on $\beta$-o-4 lignin model compound. 1. Structural characterization of the reaction products," Holzforschung 51(4), 316-324.

Lin, L. Z., Yao, Y. G., Yoshioka, M., and Shiraishi, N. (1997b). "Liquefaction mechanism of lignin in the presence of phenol at elevated temperature without catalysts: Studies on $\beta$-o-4 lignin model compound. 2. Reaction pathway," Holzforschung 51(4), 325-332.

Lin, L. Z., Yao, Y. G., Yoshioka, M., and Shiraishi, N. (1997c). "Liquefaction mechanism of lignin in the presence of phenol at elevated temperature without catalysts: Studies on $\beta$-o-4 lignin model compound. 3. Multi-condensation," Holzforschung 51(4), 333-337.

Lin, L. Z., Yao, Y. G., Yoshioka, M., and Shiraishi, N. (2004). "Liquefaction mechanism of cellulose in the presence of phenol under acid catalysis," Carbohydrate Polymers 57(2), 123-129.

Liu, Y. H., Gao, L. L., Luo, A. X., Ruan, R. S., and Liu, C. M. (2008). "Polyurethane foams made from combined liquefaction mixtures of bamboo residues and starch," ACTA Polymerica Sinica (6), 544-549.

Ma, X. J., and Zhao, G. J. (2008). "Structure and performance of fibers prepared from liquefied wood in phenol," Fibers and Polymers 9(4), 405-409.

Markova, I., and Klement, I. (2003). "Thermal analysis (TG, DTG and DSC) of hornbeam wood after drying," Wood Research 48(1-2), 53-61.

Niu, M., Zhao, G. J., and Alma, M. H. (In press). "Molecular mechanism of condensation reaction during wood liquefaction with polyhydric alcohols-chemical groups, crystallinity and microcosmic morphological characteristics of the residues," $J$. Beijing Forestry University.

Pan, H., Shupe, T. F., and Hse, C. Y. (2007). "Characterization of liquefied wood residues from different liquefaction conditions," J. Applied Polymer Science 105(6), 3739-3746.

Pan, H., Shupe, T. F., and Hse, C. Y. (2008). "Synthesis and cure kinetics of liquefied wood/phenol/formaldehyde resins," J. Applied Polymer Science 108(3), 1837-1844. 
Pu, S. J., and Shiraishi, N. (1993). "Liquefaction of wood without a catalyst 1. Time course of wood liquefaction with phenols and effects of wood/phenol ratios," Mokuzai Gakkaishi 39(4), 446-452.

Wang, G., Li, W., Li, B. Q., and Chen, H. K. (2008). "TG study on pyrolysis of biomass and its three components under syngas," Fuel 87(4-5), 552-558.

Wang, M. C., Xu, C. B., and Leitch, M. (2009). "Liquefaction of cornstalk in hotcompressed phenol-water medium to phenolic feedstock for the synthesis of phenolformaldehyde resin," Bioresource Technology 100(7), 2305-2307.

Wu, Y. M., Zhao, Z. L., Li, H. B. and He, F. (2009). "Low temperature pyrolysis characteristics of major components of biomass," J. Fuel Chemistry and Technology 37(4), 427-432.

Yamada, T., Hu, Y., and Ono, H. (2001). "Condensation reaction of degraded lignocellulose during wood liquefaction in the presence of polyhydric alcohols," $J$. Adhesion Society of Japan 37(12), 471-478.

Yan, H. P., Lu, X. X., and Qin, T. F. (1997). "Study on chemical kinetics of wood pyrolysis by thermogravimetric analysis," China Wood Industry 11(2), 14-18.

Zhang, Y. C., Ikeda, A., Hori, N., Takemura, A., Ono, H., and Yamada, T. (2006). "Characterization of liquefied product from cellulose with phenol in the presence of sulfuric acid," Bioresource Technology 97(2), 313-321.

Zhou, C. G., Li, G. Z., and Gong, A. J. (2000). "Study on the thermal stability of organosilicon-phenolic resin," Polymer Material Science \& Engineering 16(1), 164$165,168$.

Zou, X. W., Yang, Z., and Qin, T. F. (2009). "FTIR analysis of products derived from wood liquefaction with 1-octanol," Spectroscopy and Spectral Analysis 29(6), 15451548 .

Article submitted: November 2, 2010; Peer review completed: December 23, 2010;

Revised version received: December 24, 2010; Accepted: January 5, 2011; Published: January 10, 2011. 